\title{
Unbiased Scientific Approaches to the Study of Terroir Are Needed!
}

\author{
Luca Brillante $^{1 *}$, Antonello Bonfante ${ }^{2}$, Robert G.V. Bramley ${ }^{3}$, Javier Tardaguila ${ }^{4}$ and \\ Simone Priori ${ }^{5}$ \\ ${ }^{1}$ Department of Viticulture and Enology, California State University Fresno, Fresno, CA, United States, ${ }^{2}$ National Research \\ Council, Institute for Mediterranean Agricultural and Forest Systems, CNR-ISAFOM, Portici, Italy, ${ }^{3} \mathrm{CSIRO}$, Waite Campus, Glen \\ Osmond, SA, Australia, ${ }^{4}$ Televitis Research Group, University of La Rioja, Logroño, La Rioja, Spain, ${ }^{5}$ Department of Agriculture \\ and Forest Sciences (DAFNE), University of Tuscia, Viterbo, Italy
}

Keywords: zoning, geographical indications, climate change, precision viticulture, vitis vinifera L. (grapevine), wine

\section{OPEN ACCESS}

Edited by: Alexandra V. Turchyn, University of Cambridge,

United Kingdom

Reviewed by:

Claudiu Bunea,

University of Agricultural Sciences and Veterinary Medicine of

Cluj-Napoca, Romania

Robert Edwin White,

The University of Melbourne, Australia

${ }^{*}$ Correspondence:

Luca Brillante

lucabrillante@csufresno.edu

Specialty section: This article was submitted to Biogeoscience,

a section of the journal

Frontiers in Earth Science

Received: 29 February 2020 Accepted: 30 September 2020 Published: 06 November 2020

Citation:

Brillante L, Bonfante A, Bramley RGV Tardaguila J and Priori S (2020)

Unbiased Scientific Approaches to the

Study of Terroir Are Needed!.

Front. Earth Sci. 8:539377.

doi: 10.3389/feart.2020.539377

\section{THE CONCEPT OF TERROIR: USE AND ABUSE}

Terroir is a French term with roots in the Latin term terra meaning ground or land. In the international wine jargon, the term has assumed a more specific and nuanced meaning: it is the result of "collective knowledge of the interactions" between the environment and the vines mediated through human action and "providing distinctive characteristics" to the final product (i.e., wine; OIV, 2010). Terroir is not just a geographical site, but includes:

(i) the physical environment (e.g., climate, geology, soil, and topography);

(ii) the biological material and production practices;

(iii) cultural, socio-economical and political aspects.

Nowadays, the storytelling of terroir is abundant in both the popular press and marketing of wine. Although there is no reference to wine quality in the description of the terroir concept (OIV, 2010), wines which may be associated with a single vineyard are often deemed superior, although wines derived from multiple sites may also be highly regarded (Bramley, 2017).

According to OIV, 2010, which should be considered an accepted definition, terroir is a loose interpretation of a protected designation of origin (PDO), thus questioning the need for a winespecific term. For example, in the regulation of the European Union (EC No. 510/2006 Art. 2.1(a), Council of the European Union, 2006), in order to benefit from PDO status, an agricultural product needs to:

i) originate and be produced, processed and prepared in the defined geographical area and

ii) have "quality or characteristics essentially or exclusively due to a particular geographical environment with its inherent natural and human factors."

The concept of geographical origin can be used in all crops and foods, and PDOs are defined and regulated. Conversely, the terroir interpretation applies mostly to wine and is not regulated, which leaves it open to abuse and self-assessment without control, scientific evidence or socio-historical recognition (Matthews, 2016). As a result, in the current popular use, the term terroir has erroneously become jargon for vineyard site.

A designation of origin is a strict regulation. In order to maintain characteristics related to the place and the traditional practices, PDO products are made according to production standards, and are evaluated before introduction to the market, to ensure conformity to the important and distinctive characteristics that are the reason for the designation. It should be clear that, when 
including all aspects, a PDO is a product that brings a sense of place (although, PDO delineation most commonly follows political boundaries and not the limits derived from scientific understandings). Reverse engineering of geographically designated products may be straightforward, but it is definitely harder to recreate the collective knowledge, the human and cultural aspects, which are crucial to the past but also the future developments of food.

\section{SCIENTIFIC APPROACHES}

The predominant scientific focus of terroir research is on the relationships between plants and the environment, driven by site variability, and the effects of production methods, in interaction with the environment, on crop composition (van Leeuwen et al., 2004). Somewhat confusingly, in wine science, this specific branch that does not include cultural or socio-economical aspects, is also referred to using the term terroir. Terroir de base (Deloire et al., 2005), or less confusingly, a "functional zone" is the smallest area where it is possible to objectively describe the effect of environment on plant physiology and agricultural production, and which could be differentially managed (Bramley, 2005; Acevedo-Opazo et al., 2008; Bonfante et al., 2015; Brillante et al., 2016a; Brillante et al., 2017; Priori et al., 2019; Bramley, 2020). The approach to studying relationships between terroir and wine peculiarities is scale dependent, as different factors influence agricultural choices and vine performance at the regional or the within vineyard level (Vaudour, 2002). Recently, the science on the topic has shifted from a largely descriptive regional science to a technical research field, focused on the study of variation in the biophysical characteristics of the vineyard site (soil, climate, topography, etc.) and its interaction with vine performance; much of this work has involved precision agriculture methodologies (Bramley, 2020 and references therein). Currently, most of this biophysical research relating to terroir is based on zoning and the description of plant-environment interactions at a given site (Vaudour et al., 2015; White, 2020).

The science of describing site-specific relationships between the physical environment, the vine and the wine has a shorter life than the social and historical recognition of regions and vineyards. A better scientific understanding of the mechanisms ruling vineyard variability and grape quality (also with more fundamental biological approaches, e.g., Tramontini et al., 2013; Dal Santo et al., 2018) would definitely benefit all players in the industry, from producers to marketers and wine writers in both the "New" and the "Old World." We would expect the science to be a critical and proactive investigation, using current understanding of viticultural systems to provide directions for managing the quality of wines or suggesting more efficient viticultural practices; and not simply serving the role of justifying the status quo preferred by wine writers and wine marketers of iconic wines and regions.

The identification and mapping of agricultural sites with similar characteristics from a physical point of view, also called zoning, is the first step in defining a designated area and has crucial importance also in precision and sustainable agriculture, with positive economic implications. Furthermore, the availability of spatial-temporal data obtained through affordable and rapid sensing technologies has paved the path to an efficient delineation of within-field variability so that this scale of study has become more valuable to growers for management purposes. The adoption of precision viticulture and variable rate technologies is presently exploding, but issues persist in data synthesis from multiple and not always reliable sources, and with the practical implementation of information obtained (Vaudour et al., 2015).

Agricultural zoning procedures applied at different spatial scales enable site-specific planning and contribute to the optimization of management in vineyard agroecosystems. Site-specific management is expected to improve the efficiency of production (Bramley et al., 2011; Tardaguila et al., 2011; Bramley, 2020), while the optimization of agricultural decisions according to the site characteristics is likely to enhance the peculiarities of the product that depend on these characteristics.

There is no unique zoning method. Sometimes the quantitative link between the soil-plant-atmosphere system and wine only relies on empirical description, but instead, it should be analyzed with regard to its spatial structure and spatiotemporal patterns (Brillante et al., 2016a; Brillante et al., 2016b; Bramley, 2017; Brillante et al., 2017) and causal relationships (Bonfante et al., 2011; Bonfante et al., 2015; Bonfante et al., 2018). In other words, the terroir concept has often been treated and accepted as a "black box" or a marketing construct in which the relationships between a wine and its origin have not been clearly elucidated. There is a need for more and new multidisciplinary approaches in terroir analysis and zoning, to study the effects of soil, plant and climate systems on the characteristics of wines, and their resilience to stressors such as climate change. It is accepted that elements of what is needed have been researched in the context of improved viticultural management. But here our focus is on understanding terroir with the view that through such understanding, our ability to manage the production of wines of desired style will be enhanced (e.g., Bramley, 2017). Quantitative dynamic and spatial modeling approaches are likely an essential part of such research.

\section{FUTURE DIRECTIONS}

Reflecting the origin and production methods is a property of all wines. The whole industry will therefore benefit from an enhanced understanding of the mechanisms regulating the effects of the site on the wine free from dogmas and preconceptions based on our current assumptions. Knowledge that was often derived by the description of specific conditions in geographically limited places, and is likely hard to scale across space and time, especially given the current change in climate is no longer sufficient. For example, soil hydraulic properties are clearly an important element of terroir (Seguin, 1986; Choné et al., 2001; van Leeuwen et al., 2004; Bonfante et al., 2011; Bonfante et al., 2018), yet their importance relative to other 
factors may depend on whether irrigation is a part of the production system as in dry areas where rainfall is not sufficient.

A key factor in the production of winegrapes is the conditions during ripening. This derives from the fact that the current notion of terroir effects originated from the historical viticultural areas of Europe, predominantly located at high latitudes and presenting limiting growing conditions because of relatively short growing seasons, rain and cold weather. In such environments, soil conditions that enhance ripening, independently of seasonal effects, facilitate consistent quality and have been associated with presence of water or nitrogen deficits (van Leeuwen and Seguin, 2006). Such stresses have been thought to enhance the composition of grapes primarily as a consequence of the acceleration in ripening, effects on secondary pathways (Castellarin et al., 2007a; Castellarin et al., 2007b) and also for the fact that they promote an ability to harvest fruit before any incidence of rot. Such considerations may be less important in other viticultural regions (e.g., predominantly dry areas such as Australia, California, and Southern Europe), where quality wine is nevertheless produced and recognized to be representative of its origins. There is much to understand about site-specific relationships and effects on grape composition beyond the role of variability in major drivers of plant physiology (water and nitrogen) and their effects on ripening status and kinetics; these should be investigated in future studies in both "Old World" and "New World" terroirs.

Plant water availability has for a long time being recognized as a major driver in the production of fine wines (Seguin, 1986), yet irrigated vineyards under uniform management have been shown to exhibit within-vineyard variations (e.g., Bramley et al., 2011; Brillante et al., 2017); that is, and given the associated demonstrated variation in vine vigor and fruit composition, the use of irrigation has not dulled the effect of the site. Similarly, all vineyards are fertilized in one way or another and higher nitrogen supply is considered necessary to high quality white wines (des Gachons et al., 2005), yet crop nutrition is rarely mentioned as a driver of terroir (Costantini et al., 2013; White, 2020). It is obvious that with excess nutrition and water, a large part of the environmental influence on plant physiology response may be eliminated, eventually flattening out a portion of the variability in grape composition between sites. Other cultural practices would have the same effect if drastically applied, but reasoned and moderate applications would not compromise differences between sites, even at the withinvineyard scale (Brillante et al., 2017).

\section{REFERENCES}

Acevedo-Opazo, C., Tisseyre, B., Guillaume, S., and Ojeda, H. (2008). The potential of high spatial resolution information to define within-vineyard zones related to vine water status. Precis. Agric. 9 (5), 285-302. doi:10.1007/s11119-008-9073-1

Bonfante, A., Agrillo, A., Albrizio, R., Basile, A., Buonomo, R., De Mascellis, R., et al. (2015). Functional homogeneous zones (fHZs) in viticultural zoning procedure: an Italian case study on Aglianico vine. SOIL 1, 427-441. doi:10. 5194/soil-1-427-2015

Bonfante, A., Basile, A., Langella, G., Manna, P., and Terribile, F. (2011). A physically oriented approach to analysis and mapping of terroirs. Geoderma 167-168, 103-117. doi:10.1016/j.geoderma.2011.08.004
We should not neglect that climate change will definitely impose a huge challenge on our current understandings and traditions, that will most likely also affect terroirs. In theory, the concept is dynamic, meaning that growers would adapt to changing conditions to preserve the unique character of their wine (van Leeuwen et al., 2013). However, it is not clear how the whole system will be affected, especially in heavily regulated viticulture areas where vineyards are ranked in a non-mutable way. Will these ranks, and the claimed superiority of specific sites withstand the effects of climate change? Not all aspects will be challenged in the same way. The core of the concept is independent from changes (site variability will always influence the final product although in different ways), but the social/historical recognition is not; will social appreciation change if varietal composition changes? For this same reason, it would be wise to abandon the idea of arbitrary climatic limits for the production of fine wines which express their place (van Leeuwen and Seguin, 2006), the validity of which has never been scientifically demonstrated.

The science of grapes and wines risks entering a seIfreferential bubble if it does not acknowledge that other crops are doing the same with different names. It is important to keep in mind that what really matters is the idea that variability in the environment affects agricultural production. This variability can be identified and managed to smooth differences when the goal is uniformity and consistency across vintages or to enhance differences when trying to produce distinctive wines. This is possible only through the development of fundamental, objective and unbiased understandings of vine-environment relationships and their application through precision agriculture techniques. That is, both wine research and wine production should rely on science rather than myths. Accordingly, communication of terroir to consumers should be based on evidence. Such an approach can only reinforce the concept of terroir and ensure its persistence and utility, even in instances where this relates primarily to the marketing of wines.

\section{AUTHOR CONTRIBUTIONS}

All authors contributed to the writing and reviewing of this manuscript.

Bonfante, A., Monaco, E., Langella, G., Mercogliano, P., Bucchignani, E., Manna, P., et al. (2018). A dynamic viticultural zoning to explore the resilience of terroir concept under climate change. Sci. Total Environ. 624, 294-308. doi:10.1016/j. scitotenv.2017.12.035

Bramley, R. G. V. (2005). Understanding variability in winegrape production systems 2. Within vineyard variation in quality over several vintages. Aust. J. Grape Wine Res. 11, 33-42. doi:10.1111/j.1755-0238.2005.tb00277.x

Bramley, R. G. V. (2017). "Making sense of a sense of place," in Proceedings of the 16th Australian wine industry conference, adelaide, south Australia, Adelaide, South Australia, July 2016. Editors K. S. Beames, E. M. C. Robinson, P. R. Dry, and D. L. Johnson (Urrbrae, South Australia: Adelaide: The Australian Wine Industry Technical Conference Inc.), $45-51$. 
Bramley, R. G. V. (2020). "Precision viticulture: managing vineyard variability for improved quality outcomes," in Managing wine quality: viticulture and wine quality. New York, NY: Elsevier, Vol. 1. doi:10.1016/C2016-0-02279-9.

Bramley, R. G. V., Ouzman, J., and Boss, P. K. (2011). Variation in vine vigour, grape yield and vineyard soils and topography as indicators of variation in the chemical composition of grapes, wine and wine sensory attributes. Aust. J. Grape Wine Res. 17, 217-229. doi:10.1111/j.1755-0238. 2011.00136.x

Brillante, L., Bois, B., Lévêque, J., and Mathieu, O. (2016a). Variations in soil-water use by grapevine according to plant water status and soil physical-chemical characteristics-A 3D spatio-temporal analysis. Eur. J. Agron. 77, 122-135. doi:10.1016/j.eja.2016.04.004

Brillante, L., Mathieu, O., Lévêque, J., and Bois, B. (2016b). Ecophysiological modeling of grapevine water stress in burgundy terroirs by a machine-learning approach. Front. Plant Sci. 7, 1-13. doi:10.3389/fpls.2016.00796

Brillante, L., Martínez-Luscher, J., Yu, R., Plank, C. M., Sanchez, L., Bates, T. L., et al. (2017). Assessing spatial variability of grape skin flavonoids at the vineyard scale based on plant water status mapping. J. Agric. Food Chem. 65, 5255-5265. doi:10.1021/acs.jafc.7b01749

Castellarin, S. D., Matthews, M. A., Di Gaspero, G., and Gambetta, G. A. (2007a). Water deficits accelerate ripening and induce changes in gene expression regulating flavonoid biosynthesis in grape berries. Planta 227, 101-112. doi:10.1007/s00425-007-0598-8

Castellarin, S. D., Pfeiffer, A., Sivilotti, P., Degan, M., Peterlunger, E., and Di Gaspero, G. (2007b). Transcriptional regulation of anthocyanin biosynthesis in ripening fruits of grapevine under seasonal water deficit. Plant Cell Environ. 30, 1381-1399. doi:10.1111/j.1365-3040.2007.01716.x

Choné, X., van Leeuwen, C., Dubourdieu, D., Gaudillère, J. P., and Gaudillere, J. P. (2001). Stem water potential is a sensitive indicator of grapevine water status. Ann. Bot. 87, 477-483. doi:10.1006/anbo.2000.1361

Costantini, E. A. C., Agnelli, A., Bucelli, P., Ciambotti, A., Dell'Oro, V., Natarelli, L., et al. (2013). Unexpected relationships between $\delta{ }^{13} \mathrm{C}$ and wine grape performance in organic farming. J. Int. Sci. Vigne Vin 47, 269-285. doi:10. 20870/oeno-one.2013.47.4.1556

Council of the European Union (2006). Council Regulation (EC) No 510/2006 of 20 March 2006 on the protection of geographical indications and designations of origin for agricultural products and foodstuffs. Brussels, Belgium: Council of the European Union.

Dal Santo, S., Zenoni, S., Sandri, M., De Lorenzis, G., Magris, G., De Paoli, E., et al. (2018). Grapevine field experiments reveal the contribution of genotype, the influence of environment and the effect of their interaction $(\mathrm{G} \times \mathrm{E})$ on the berry transcriptome. Plant J. 93, 1143-1159. doi:10.1111/tpj.13834

Deloire, A., Vaudour, E., Carey, V., Bonnardot, V., and Van Leeuwen, C. (2005). Grapevine responses to terroir: a global approach. J. Int. Sci. Vigne Vin 39, 149-162. doi:10.20870/oeno-one.2005.39.4.888

des Gachons, C. P., van Leeuwen, C., Tominaga, T., Soyer, J. P., Gaudillère, J. P., and Dubourdieu, D. (2005). Influence of water and nitrogen deficit on fruit ripening and aroma potential of Vitis vinifera $\mathrm{L} \mathrm{cv}$ Sauvignon blanc in field conditions. J. Sci. Food Agric. 85, 73-85. doi:10.1002/jsfa.1919

Matthews, M. A. (2016). Terroir and other myths of winegrowing. Berkeley, CA: University of California Press.

OIV (2010). General assembly of the international organisation of vine and wine. Resolution OIV/VITI 333/2010. Paris, France: OIV.

Priori, S., Pellegrini, S., Perria, R., Puccioni, S., Storchi, P., Valboa, G., et al. (2019). Scale effect of terroir under three contrasting vintages in the Chianti Classico area (Tuscany, Italy). Geoderma 334, 99-112. doi:10.1016/j.geoderma.2018.07.048

Seguin, G. (1986). "Terroirs" and pedology of wine growing. Experientia 42, 861-873. doi:10.1007/bf01941763

Tardaguila, J., Baluja, J., Arpon, L., Balda, P., and Oliveira, M. (2011). Variations of soil properties affect the vegetative growth and yield components of "Tempranillo" grapevines. Precis. Agric. 12, 762-773. doi:10.1007/s11119-011-9219-4

Tramontini, S., van Leeuwen, C., Domec, J. C., Destrac-Irvine, A., Basteau, C., Vitali, M., et al. (2013). Impact of soil texture and water availability on the hydraulic control of plant and grape-berry development. Plant Soil 368, 215-230. doi:10.1007/s11104-012-1507-x

van Leeuwen, C., Friant, P., Choné, X., Tregoat, O., Koundouras, S., and Dubourdieu, D. (2004). Influence of climate, soil, and cultivar on terroir. Am. J. Enol. Vitic. 55, 207-217.

van Leeuwen, C., Schultz, H. R., Garcia de Cortazar-Atauri, I., Duchene, E., Ollat, N., Pieri, P., et al. (2013). Why climate change will not dramatically decrease viticultural suitability in main wine-producing areas by 2050. Proc. Natl. Acad. Sci. U. S. A. 110, E3051-E3052. doi:10.1073/pnas.1307927110

van Leeuwen, C., and Seguin, G. (2006). The concept of terroir in viticulture. J. Wine Res. 17, 1-10. doi:10.1080/09571260600633135

Vaudour, E. (2002). The quality of grapes and wine in relation to geography: notions of terroir at various scales. J. Wine Res. 13, 117-141. doi:10.1080/ 0957126022000017981

Vaudour, E., Costantini, E., Jones, G. V., and Mocali, S. (2015). An overview of the recent approaches to terroir functional modelling, footprinting and zoning. SOIL 1, 287-312. doi:10.5194/soil-1-287-2015

White, R. E. (2020). The value of soil knowledge in understanding wine terroir. Front. Environ. Sci. 8. doi:10.3389/fenvs.2020.00012

Conflict of Interest: The authors declare that the research was conducted in the absence of any commercial or financial relationships that could be construed as a potential conflict of interest.

Copyright (๑) 2020 Brillante, Bonfante, Bramley, Tardaguila and Priori. This is an open-access article distributed under the terms of the Creative Commons Attribution License (CC BY). The usedistribution or reproduction in other forums is permittedprovided the original author(s) the copyright owner(s) are credited that the original publication in this journal is citedin accordance with accepted academic practice. No usedistribution or reproduction is permitted which does not comply with these terms. 